Review Article

\title{
Food Adulteration and Some Methods of Detection, Review
}

\author{
Misgana Banti \\ Ethiopian Institute of Agricultural Research, Jimma Agricultural Research Centre, Jimma, Ethiopia \\ Email address: \\ misganabanti2013@gmail.com
}

\section{To cite this article:}

Misgana Banti. Food Adulteration and Some Methods of Detection, Review. International Journal of Nutrition and Food Sciences. Vol. 9, No. 3, 2020, pp. 86-94. doi: 10.11648/j.ijnfs.20200903.13

Received: May 25, 2020; Accepted: June 9, 2020; Published: June 23, 2020

\begin{abstract}
Most of the Foods we are having are prone to food fraud and adulteration. Food adulteration is either the addition of a non-food item to increase the quantity of raw or prepared food intentionally or non food substances added accidentally. Food adulteration also includes any poisonous or deleterious substances which may render the food injurious to health. Food adulteration can be either the act of addition, removing valuable food component or substitution of these valuable ingredients with relatively less expensive (cheaper) substances for unfair economic gain. This act of food fraud may be an economic gain for the manufacturer, while it is loss for the final consumers of the products. While buying and serving an adulterated foods, consumers are affected in different ways; they may not getting the intended food nutrients, the adulterated foods may be unsafe for health and it can also be economic loss to the consumers. There are different food known to be prone to adulteration both in our country Ethiopia and the world including milk, meat, injera in our country, Ethiopia, honey, butter, juices, and etc as examples. There was a report through media outlet very recently in Ethiopia about adulteration of injera with saw dust. There are different methods through which food adulteration can be detected. These methods include physical, chemical, biochemical, and other techniques. Detection of food adulterant is more difficult when both adulterant and the food itself have approximately the same physiochemical makeup. Adulterations of food interfere with consumers' right to get safe and good quality foods. So, all responsible individuals, organization, including government should fulfill their responsibility to protect the act of food adulteration and to expose the identified acts. Moreover, researchers and academia working in different research institute have many gaps to address related to the topic including assessment of the status, identification of foods susceptible for adulteration in the context of the country, development and validation of detection methods and much more.
\end{abstract}

Keywords: Adulteration, Fraud, Intentional, Incidental, Replacement, Substitution

\section{Introduction}

Food is stuff of either plant or animal origin which in raw, processed or semi-processed form will taken in to the body in order to support the different biochemical and physiological activities of our body. Most of the times, these foods are prone to food fraud and adulteration, and put health disorder to consumers. The term food fraud encompasses the deliberate substitution, addition, tampering or misrepresentation of food, food ingredients or food packaging, or false or misleading statements made about a product for economic gain. The specific type of fraud is the fraudulent, addition of fake substances or removal or replacement of genuine substances without the purchaser's knowledge for economic gain by the seller. Though traditionally, people cook and eat foods with health process and incidents at home, in modern times, change in life styles and raise in income leads more and more peoples to have ready to eat foods at restaurant on regular basis [1]. The food in numerous of these outlets may have been cooked with poor quality while still attract and satisfy the palate rather than provide a wholesome nutritional meal. Nevertheless, normally most people do not know these foods are adulterated by 25 to 30 percent as implied by the above authors. This causes a major impairment for the health these consumers.

Quality and safety of food including the factors affecting them have major rising areas within the food supply chain and attracted attentions of researchers, government and regulatory bodies [6]. Food adulteration is one among these different emerging areas of science. The word adulteration can be viewed in different ways, either mixing or substitution of inferior 
substances to the one which is superior to the adulterants or removal of some of valuable constituents from a given food products [20]. The term adulterated in legal term is used to mean that a food product fails to meet federal or state standards. Adulteration can also be the addition of a non-food item to increase the quantity of the food in raw or prepared form, preservation purpose, and improvement of appearance which can be done either intentionally or unintentionally. Also included are any poisonous or deleterious substances which may render the food injurious to health. Examples would be adding water to milk or animal carcasses to meat products other than the animal meant to be consumed, stones, gravel sand, insects, or animal hairs to grain products. So, one among the definitions of food adulteration is that it is an act of intentionally debasing the quality of food offered for sale. Consumers are always either at least sufferers of being cheated or even victims of disease as a result of adulteration of food stuffs and death to the worst. So, knowing common types of foods to be adulterated, common adulterants and health implications of the different adulterants are very important to the consumer [2].

Adulterants can also be elaborated as chemical substances which should not be contained within a given food or beverage; but, may be intentionally added to more expensive substances to increase visible quantities and reduce manufacturing costs, or for some other deceptive or malicious purpose [2]. The act of adulteration was more common in societies from very ancient time with few legal controls on food quality due to poor or nonexistent monitoring by authorities. Sometimes the act of adulteration may even extended to exceedingly dangerous chemicals and poisons. More recently for example, [13] stated that, in the People's Republic of China (Chinese milk scandal case with melamine) in which some children killed and thousands were harmed and has attracted much public attention. Thus, food adulteration is still becoming one of the significant public health issues in different countries. The malpractice of adding harmful chemicals in food items is not only impacting on consumers' health but also destroying the nutritional compositions of food [16].

The issue of adulteration in our country is also not less important as compared to other countries, except the fact that there is limited reported literature and research done in the area due to different issues related to awareness, resources, attentions and others. Even the available limited literatures are found in dispersed forms and hence needed to be collected and compiled in more organized review forms. This reviewing of literature concerning such issue is extremely important because, it will make easy to know what have been identified and done so far in the area and to identify gaps for further research. Hence, this review paper was prepared by reviewing different sources related to adulteration and put some future line of work, so that it will be focal pints of research for the future.

\section{History of Adulteration}

The usage of adulterants has been common in societies with few legal controls on food quality and hence poor or even nonexistent monitoring by authorities. During the times prehistory, humans have altered the state of food to extend its longevity or improve its taste [18]. According to this author, as early as 300,000 years ago, early humans had used fire to cook and conserve meat. Later on, it was identified that salt could be added to preserve meat without cooking. Wine was often mixed with honey, herbs, spices and even saltwater, chalk or lead, which served as both a sweetener and a preservative in ancient Rome and Greece. The act of adulterating food for economic gain began to emerge as time goes on. During the Middle Ages, imported valuable and high prices spices were of high demand and limited supply. Thus, merchants sometimes started to combine it with nutshells, pits, seeds, juniper berries, and stones or dust [18]. Accordingly, contemporary accounts of adulteration date from the 1850 s to the present day. Adulteration was thought to be first investigated in 1820 by the German chemist Frederick Accum, who identified many toxic metal colorings in foods and drinks. Later on physician Arthur Hill Hassall carried out extensive research in the early $1850 \mathrm{~s}$, which led to the 1860 food adulteration act and further legislations [18].

\section{Types of Adulteration}

Literature [8] defined adulteration as the act of debasing product with the objective of counterfeiting a pure or genuine commodity or of substituting an inferior article for a superior one in order to gain an illegitimate profit. In addition, the authors list four ways of adulteration [8]. These are:

Addition of extraneous matter, example addition of sand to food grains and water to milk;

Mixing inferior quality material with a superior one, example mixing used/spent tea leaves with fresh tea leaves

The use of prohibited dyes and preservatives, example coloring of spices;

Extraction of valuable ingredients, for example, abstraction of fat from milk or oils from spices.

Thus, food is said to be adulterated if any of the following happened to it [8]:

A substance is added which decreases its value or makes it injurious.

Less expensive or inferior substances are substituted wholly or in part.

Any valuable constituents have been subtracted either entirely or in part.

In case it is counterfeiting (imitation).

In case colored or otherwise treated to improve its appearance with stuff injurious to health

No matter what the reason is, if its quality is below the standard.

Food in general is adulterated for different reasons. Some organizations or individuals in food supply chains are adding adulterants to foods for improving the appearance to get better price by cheating buyers of the products. Food can also adulterated for increasing volume, preserving or others. Generally, adulterations can be intentional and unintentional $([4,13,10]$ and $[11])$.

\subsection{Intentional Adulteration}

Intentional food adulteration is purpose fully performed 
type of adulteration and is usually done for financial gain. The most frequent type of adulteration of this category is color adulteration. The examples of the intentional adulteration are the addition of water to liquid milk, extraneous matter to ground spices, or the removal or substitution of milk solids from the natural product. It includes, adding things like sands, marble chips, stones, mad, other filth, chalk powder, water, mineral oil, and harmful color to earn some unfair profit ([19] and [25]). Addition of water or urea to liquid milk, extraneous matter to ground spices, addition of argemone seeds to mustard seeds, washing powder to ice creams, chalk to sugar, water to honey, chicory to coffee, white powered stone to common salt, argemone oil to groundnut oil are all intentional adulterations reported from different parts of the world ([12] and [19]). It is dangerous because, amounts of nutrients deducted and extraneous substances added into food items that are done by business oriented people just forgetting the humanity behind of money making mentality [3].

According to [17], olive oil, milk, honey, saffron, orange juice, coffee and apple juice are the seven most likely food to be targets for intentional or economically aggravated use of adulterants in food, or food fraud as of the first U.S. public database created to compile information on risk factors for food fraud. Calcium carbide used in mangoes, bananas, copper sulfate used to ripen fruits faster, oxytocin a harmone used for faster growth of Pumpkin, watermelon, gourds, cucumber, wax to add shine on apples and pears, cheap green colors containing chemicals such as metallic lead applied to bitter gourd and leafy vegetables to give fresh color, pesticides and herbicides used excessively for growing fruits and vegetables can all be considered adulterants if not well communicated to consumer [19].

\subsection{Incidental Adulteration}

Unintentional (incidental) adulteration is a result of ignorance or the lack of facilities to maintain food quality. This may be caused by leak out effect or from pesticides and fertilizers. Inappropriate food handling and packaging methods can also result in these types of adulterations. Accidental food adulteration as the name imply occurs accidentally (incidentally) without our knowledge [19]. Authors further elaborate that, a variety of green vegetables is grown in areas of industries and these areas have high levels of industrial pollutants, including heavy metals, which are absorbed by the plants and hence, food adulteration occurs accidentally is expected. Pesticide residues, droppings of rodents, larvae in foods are examples of adulterants under this category [25]. This type of adulteration is brought due to lack of proper hygienic conditions of food products and drinks throughout production site to consumption table. Here, the producers or traders are not in position to add different adulterants but the ways the products are produced, handled, passed, and processed, stored, transported and marketed may be the places where they were contaminated or adulterated since any substance without its original is extraneous to the product and hence is considered adulteration. These includes: residual pesticides, tin from cans, rodent droppings, preservatives, mercury from effluents, lead from water, etc., ([10] and [4]).

\subsection{Metallic Contaminants}

Metallic contaminants may enter the food supply chain through environmental contamination or during food production process and they may be present in food in trace amount [10]. Arsenic from pesticides, lead from water, and effluent from chemical industries, tin from cans are some of the metallic contaminants which could be considered another incidental type of adulterants in foods [25]. The mercury from effluents, lead from water and similar contaminants are also among metallic contaminant adulteration type [10].

\subsection{Natural Adulteration}

The natural adulteration is also another type of adulteration which could take place in foods due to the presence of different chemicals, organic compounds or radicals naturally occurring in foods which are injurious to health and are not added to the foods intentionally or unintentionally [19]. From different types of natural adulterations, some examples are toxic varieties of pulses, mushrooms, green and other vegetables, fish and seafood which might be called as anti-nutrients in some of cases. Many varieties from species of marine fish are known to be toxic of which many are among edible varieties.

The act of food adulteration can also be categorized as replacement, addition or removal [25]. Replacement can be absolute or partial substitution of a food component or valuable authentic constituent with less expensive substitute with the intention of circumventing on origin and false declaration of the process in general. Addition on the other hand is the inclusion of small amount of non-authenticated substances to mask inferior quality ingredient. The removal type of adulteration is taking away of authentic and valuable constituents without purchasers' knowledge. These all are done for the economic gain. Adulteration can also occur during production of organic, genetically modified, irradiating foods [19].

\subsection{Adulteration in Organic Foods}

In case the food is claimed to be organic, it needs to be grown and manufactured in a manner that adheres to standards set by the respective country they sold in. In an organic type of farming there is no use synthetic pesticide into the environment. The most common pesticides, accepted for restricted use by most organic standards, include Bt, pyrethrum and rotenone. Therefore, any food claimed organic and not fulfilling the standards is adulterated [19].

\subsection{Adulteration During Irradiating the Foods}

In food irradiation, ionizing radiation like radionuclide Cobalt-60 is applied to food for destroying and checking the multiplication of microorganisms, bacteria, viruses, or insects that might be present in the food and for sprout inhibition, delay of ripening and improvement of rehydration as well [19]. When irradiating foods, the quantity of dosage is very much important. In ionizing radiation, there are disruptions of internal metabolism of cells, DNA cleavage, and formation of free radicals. In the process, there are disruption in chemical bonds, possible development of 
resistant microorganisms, inadequate analytical procedures to detect irradiation in food, and public resistance. If this irradiation is used at the level that it can be over dosed, then, it is obvious that it will be sever health hazards. Therefore, all these acts without knowledge of consumer can be considered adulteration.

Table 1. Irradiation doses in some foodstuff.

\begin{tabular}{lllll}
\hline \multirow{2}{*}{$\mathbf{N}^{\mathbf{0}}$} & Name of foods & \multicolumn{3}{l}{ Dose of irradiation (Kilogray, KGy) } \\
\cline { 3 - 5 } & Minimum & Maximum & 1.0 & 0.09 \\
\hline 1 & Pulses & 0.25 & 14 & 0.62 \\
2 & Onions & 0.03 & 0.75 & 10 \\
3 & Spices & 6 & 6.0 & 0.50 \\
4 & Mango & 0.25 & 1.0 & 5.00 \\
5 & Frozen Sea Foods & 4.0 & 3.0 & 0.62 \\
6 & Dried Sea Foods & 0.25 & & 2.00 \\
7 & Fresh Sea Foods & 1.0 & & \\
\hline
\end{tabular}

Source: [28]

\subsection{Adulteration during Production of Genetically Modified Foods}

Genetically modified organisms (GMOs) are organisms in which the genetic material (DNA) has been changed in a manner that does not happen in nature. It is often called modern technology or gene technology. Combining genes from different organisms is said to be genetic modification. The GM products include medicines, vaccines, food and food ingredients, feeds and fibers. Though GM foods are developed and marketed because there is some perceived advantage either to the producer or consumer of these foods; there are safety issues including allergens, transfer of antibiotic resistance markers, and unknown effects can happen. Thus, unless communicated to users, GM food could be one form of adulterations [19].

\section{Food Adulteration and Its Consequence}

\subsection{Health Problems Related to Adulteration}

Adulterated foods can leads to different health problem after consumption and considered as one of the major problem of everyday life [19]. For example, addition of argemone seeds to mustard can cause loss of vision and heart diseases.

As concluded by [7], adulterations expose the society to many diseases ranging from mild to life threatening. For example, asthma, skin diseases and cancer caused due to intake of fish, fruits, meat or milk adulterated with chemicals like formalin. Human health is highly sensitive to food adulteration and sometimes shows immediate side effects like diarrhea, dysentery and vomiting. For example, coffee powder substituted with date seed powder or tamarind can cause diarrhea [17]. According to [19], a chunk of the green leafy vegetables sold in Chennai is found to contain toxic metals that have the potential to harm various organs of the body. It is common in almost all developing countries. And their ugly faces is come out in the form of its harmful effects as stomach disorder, giddiness and join pain, diarrhea, liver disorder, dropsy, gastrointestinal problems, respiratory diseases, cardiac arrest, glaucoma, carcinogenic effects, paralysis etc. Therefore, health concern related to food adulteration as can be understood from this review includes food poisoning, stomach ache, indigestion, loose stools, cough, fever, vomiting or nausea, apthae in mouth, out of infection from adulterated food, and etc.

\subsection{Economic Impact of Adulteration}

Adulterant is rampant in poor strata of society due to consumer's illiteracy and ignorance of their rights and responsibilities towards food adulteration [15]. High incidence of food borne illness is found in families who consume adulterated food. Thus, adulterated foods may be illegal profit for those who are adulterating while it is not only expense of money for consumer but also leads to illness as well. With time, acceptance of foods in the any types of market could decrease due to destruction in originality of adulterated foods and this in turn is economic loss [5].

Table 2. Examples of purpose and harmful effects of adulterants.

\begin{tabular}{lll}
\hline Adulterant & Purpose & Harmful Effects \\
\hline Water & To increase the volume of milk & $\begin{array}{l}\text { Water polluted with feces, microorganisms and harmful chemicals may have deleterious effects } \\
\text { on human health; potential risk for water born disease. }\end{array}$ \\
Cellulose & $\begin{array}{l}\text { To increase total solids and hence the } \\
\text { quantity of the products. }\end{array}$ & $\begin{array}{l}\text { Food adulterated with such food products is not as nutritious as the original one and low } \\
\text { digestibility. }\end{array}$ \\
Proteins & $\begin{array}{l}\text { Low priced non-milk proteins such as soy, } \\
\text { pea and wheat proteins }\end{array}$ & $\begin{array}{l}\text { The expected protein will not be obtained and is not the same as what is paid for. } \\
\text { Boric acid }\end{array}$ \\
\hline
\end{tabular}

Source: [23].

The above table shows only examples of adulterants and the purpose why they are used in milk and health or nutrition implications. However, the adulterants in milk are not limited to these one, rather, there are different types of adulterants in milk as it is true for other food products. 


\section{Food Products Prone to Adulteration}

There are various food items and drinks that are prone for adulteration as revealed according to the reports of different authors across the world. That means it may be difficult to get a food items, may be flour, pulse, oil, fruit, vegetable, milk, sweet, spices, tea, coffee, honey, bakery item, chocolate, fruit juice, and the like which is free from one or the other forms of adulterants. Even animal feed like cake as protein supplement for lactating animals is adulterated which accounts about $90 \%$ of un-branded loose forms as indicated in literature [1].

\section{The Cases of Adulteration in Ethiopia}

In our country Ethiopia, varieties of foods are known to be adulterated. For instance, there is adulteration of milk and milk products that is done by some selfish producers of raw milk and majorly traders/retailers/middlemen by using several chemicals like urea and adding substances such as starch, flour, cane sugar, vegetable oils, preservatives, water, skim milk, etc [5]. This phenomenon is not limited to milk but, also to the other plant and animal food products. Food products like milk, grain, beverages, butter and etc are known to be adulterated even traditionally. For example, very recently, peoples were arrested for found while adulterating tef flour with saw dust, Jesso or 'sagatura' in local language of the country Ethiopia for making injera for sell. This information about adulteration of injera with saw dust was written in Ethiopian standard agency information media page in 2018. Even though not researched and reported scientifically, this flour for injera is also known to be adulterated even with relatively less expensive crops without the knowledge of the consumer. This indicates that, there are hidden adulterations without being reported and need attention in the future.

Literature [8] also examined different foods from different regions of Bahir Dar for adulteration. Among the food tested by the author, the butter samples collected from 4 different markets were one and were analyzed for the presence of adulterants. Based on the author's results, $6.7 \%$ of the butter samples he tested were found adulterated with vegetable sources, mainly mashed potatoes indicating a blue color. Coffee was also tested by the same author and found to be adulterated. From the results of the test, the author revealed that $8 \%$ of the samples from 5 different markets showed blue color for the presence of high concentration of starch or sugar which entails that the coffee powder is adulterated with roasted cereals. According to him, roasted cereals like barely, maize, soybean, coffee husks and straw, etc are the suspected adulterants to be used in coffee.

Honey is also another possible food product prone to adulteration. After conducting Fielen's test, the author observed cherry red color in $15 \%$ of the samples indicating that the honey was adulterated with sugar or invert sugar [8]. On his experiment on red pepper powder, the author comes up with result that $1.3 \%$ of the sample contains brick powder and grit that settled at the bottom of the sample of red pepper powder. He supported his result by citing the work by [17] who reported brick powder as the common adulterant for chilly-powder. Papaya seeds used to add bulk are also another adulterant to pepper powder as the above literatures implied. The harmful effect with this papaya seed is that Papaya seeds can cause serious liver problems and stomach disorders. Different edible oil samples were also analyzed by [8] for the presence of argimone oil and it is observed that $2.7 \%$ of his oil samples contain argimone oil because; the samples indicated reddish brown precipitate. The result of this author again is in line with that of [17] who found that argemone seeds oil which is used to add bulk and weight to edible oils proven to be carcinogenic if consumed over a long period of time.

This information of food adulteration in our country, Ethiopia indicates the needs of attention even though few research reports concerning the issue are available. For instance, [8] concludes that adulteration is becoming a serious problem in Bahir Dar area which the author stated might be a health risk for the community. As the author further stated, some of the consumers are unaware of the problem, others have no access to methods of identification and the rest are due to carelessness. The scarcity of research based information with respect to the acts of adulteration in Ethiopia implies that much work is needed ranging from the assessment of different food stuffs to searching for different possible detection methods which could be used for its identification.

\section{Detection Mechanisms of Adulterated Food}

The mechanisms of identifying the usage of adulterants in foods depends on physical, chemical, biochemical, and other techniques. All these methods, which have replaced the early organoleptic and other empirical tests, are continuously updated because food adulteration is interminable, and new problems are always arising. Different types of analytical procedures are usually employed for most cases of adulteration so that the analyst has the flexibility to choose the appropriate one (number of samples to be analyzed, sensitivity required, etc). For example, red wine adulterated with the juice of bilberries or elderberries produced a deep blue precipitate with lead acetate [17]. According to the authors also, starch in rice flour or wheat flour often added to thicken cream, could be recognized by the blue color produced by a dilute solution of iodine test in aqueous potassium iodide.

\subsection{Chemical and Biochemical Methods}

There are different designed chemical and biochemical methods for detection of adulterants which can be categorized as chromatography based, spectroscopy and immunology based and electrophoresis based [7]. According to these authors, the basic analytical approach involves various steps including extraction with a suitable solvent, cleanup for removal of interfering matrix components, chromatographic separation and selective detection.

These and other methods of detection of adulterants can be done by following the respective procedures of each of the methods. HPLC can be used as a quality control tool as it can separate various chemical constituents from mixtures; it is also 
used for characterizing food products or to detect adulteration [7]. That mean, its use in adulterant detection lies in its capacity to separate mixture of chemicals. For example, among the analytical techniques of adulterant detection, HPLC (High-performance liquid chromatography) is the most widely used technique and the procedures will follow the normal procedure of chemical determination by this instrument.

Gas chromatography (GC) is an extra apparatus for identification of adulterants and is used for separating volatile organic compounds. GC along with mass spectroscopy (MS) and Fourier transform infrared spectroscopy (FTIR) has been widely used for adulterant detection as these are non destructive techniques with respect to the sample [7]. Gas chromatography is generally used to discriminate among different varieties of the same product, adulteration detection, and organic compound authentication and identification.

Among the spectroscopic techniques, near infrared spectroscopy (NIR) helps in rapid detection of adulterants in raw material but is unable to identify the contaminant [7]. The authors further stated another detection method; nuclear magnetic resonance (NMR) which will not only detects an adulterant but also provides structural identification of the contaminant. According to [26], Atomic Absorption Spectrometry can be utilized as validation method for analysis of lead in all foods except oils, fats and extremely fatty products. A combination of chromatographic and spectroscopic techniques has also shown a high potential for detection of adulterants, for example, GC-MS has shown potential to detect honey adulteration with commercial syrups [21]. The indirect enzyme-linked immune-sorbent assay (ELISA) was also developed for the detection and quantification of bovine milk adulteration in goat's milk [27]. It has been observed that ELISA can be successfully used to determine adulteration of milk samples and thus ELISA kits will help in routine inspection of milk.

Milk and milk products adulterated with starchy products can be identified through digestion of starch by first boiling 2-3 $\mathrm{ml}$ of sample in $5 \mathrm{ml}$ of water, cooling and adding 2 to 3 drops of iodine and then formation of blue color indicates the presence of starch.

Ghee adulterated with starchy products can also be detected following the same principle.

Detection of mashed potatoes, sweet potatoes and other starches in ghee/butter can be done by taking half teaspoon of ghee/butter in a transparent glass bowl, adding two to three drops of tincture of iodine and hence, formation of blue color indicates the presence of mashed potatoes, sweet potatoes and other starches.

Milk adulteration by starchy source can be identified by heat treatment. While heat is applied, the starch will galvanize and this will be an index.
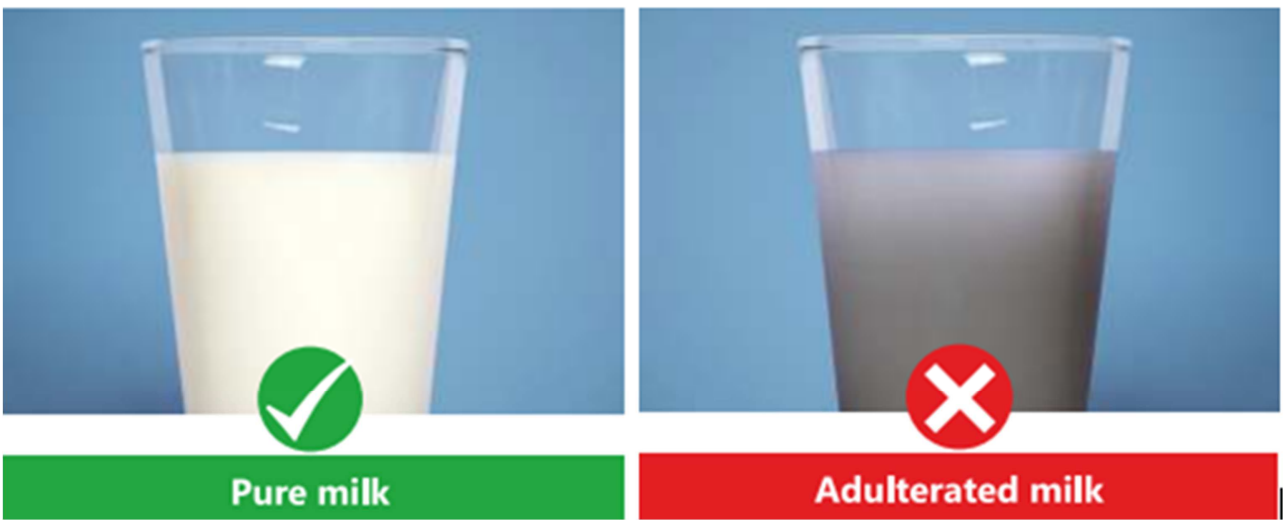

Pure milk

Figure 1. Milk adulteration detection by starch test.
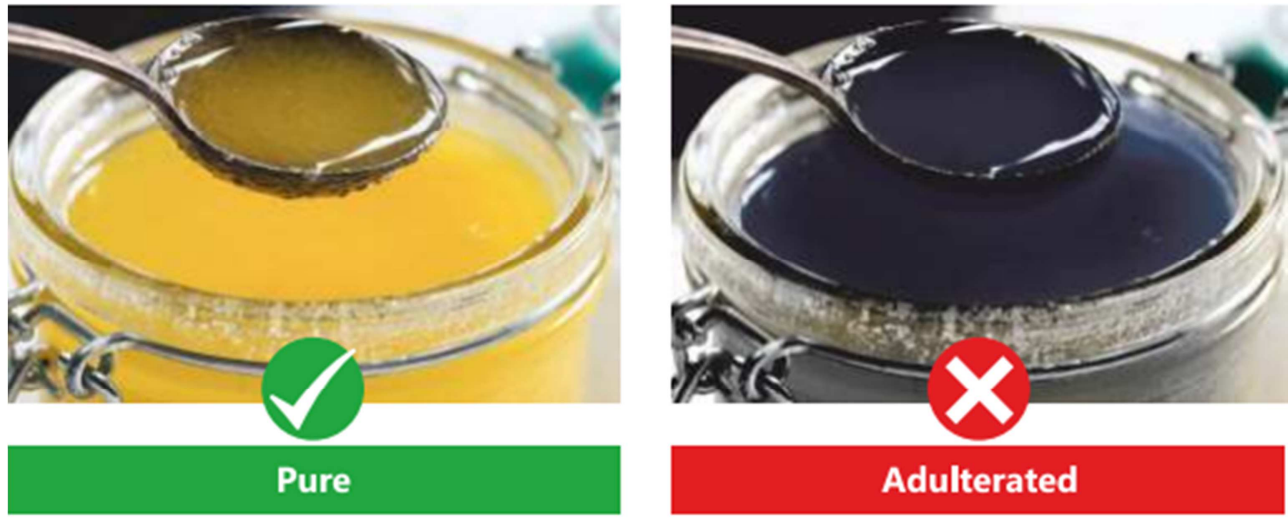

Figure 2. Butter/ghee adulteration which can be detected by simple starch test. 


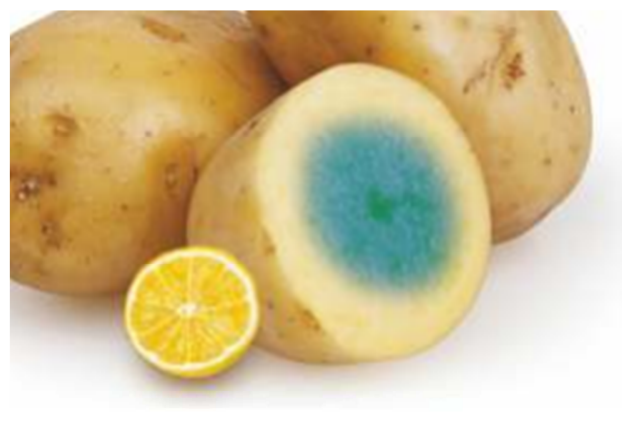

Iodised salt

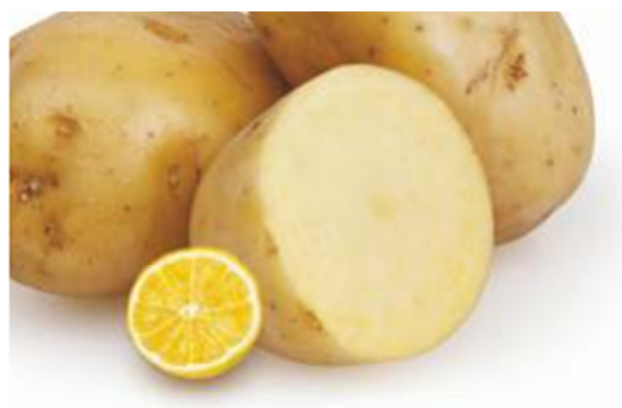

Common salt

Source: http://foodsmart.fssai.gov.in/DART.pdf.

Figure 3. Way to differentiate iodized and common salt.

If iodized salt is in need and there is worry about whether the available salt iodized or not, it can simply checked as follows. First, cutting a piece of potato, add salt and wait for a minute, add two drops of lemon juice, blue color will develop if it is iodized salt while no blue color if not.

Some examples of simple physical methods of detecting adulterants are given in the following table:

Table 3. Lists the common adulterated food staffs and simple methods to identify.

\begin{tabular}{|c|c|c|}
\hline Food product & Adulterants & Detection methods \\
\hline Mustard & Argemone seeds & Argemone seeds have rough surface $\&$ on pressing is white inside. Mustard is yellow inside \\
\hline Ice Cream & Washing Powder & Put some lemon juice, bubbles are observed if washing powder is present \\
\hline Honey & Water & $\begin{array}{l}\text { A cotton wick dipped in pure honey burns when ignited with a matchstick. Presence of water will not allow the } \\
\text { honey to burn, and if it does, it will produce a cracking sound. }\end{array}$ \\
\hline & Brick Powder & Brick powder settles fast chilli, powder settles slowly in water. \\
\hline Red Chilli Powder & Red Colour dye & $\begin{array}{l}\text { Sprinkle some Chilli powder on the surface of water in a glass beaker. Artificial colorants will descend as } \\
\text { colored streaks. }\end{array}$ \\
\hline
\end{tabular}

Source: (www.dixitsitaram.itgo.com).

Proximate analysis of a foodstuff can also indicates the extent of abstraction for the main components; moisture, fat, protein, carbohydrates, fiber, and ash. However, proximate analysis of adulterated food alone cannot answer problems of authenticity or speciation. This may be because, combination both qualitative and quantitative analysis of foods are important to be used for detection of adulteration of food ingredients and products (i.e., to authenticate the food ingredient or product) [22]. Predominantly, adulteration can be detected from the presence of minor components that occur in the adulterant and not in the food itself. Trace chemical analysis is indispensable to evaluate the purity. Data banks of authentic values that account for seasonal, regional or other variation may support authenticity testing in some cases (fruit juices for example). Detection of food adulterant is more difficult when both adulterant and the food its self have approximately the same chemical formula [9]. If this is a case, there are different approaches to detecting adulterants by overcoming the problem:

The primary approach consists of determining the ratio between some chemical constituents and assumes these ratios are a constant component of the particular food.

Searching for a specific marker in the product, which could be a chemical constituent (complexes molecules, nucleic acids) or morphological component (plant cells), that proves either the adulteration or authenticity of the food is another alternative approach.

The other method consists of using analytical techniques derived from physical analysis by considering the whole of the sample to show the effects of the adulteration on the physicochemical properties of the sample.

The different detection methods can be categorized as physical and chemical method as elaborated below. Here under, example of analytical methods used for the detection of adulteration is listed in table form.

Table 4. Analytical methods of detection.

\begin{tabular}{lll}
\hline Products & Common adulterants & Common detection methods \\
\hline Berry jam & Addition of cheaper berries & HPLC \\
Fruit juice & Dilution with water & ${ }^{\circ}$ Brix \\
Meat & Addition of cheaper meat & Electrophoresis, immunoassay \\
Vegetable oil & Addition of cheaper seed oil & Chromatography \& mass spectroscopy \\
Natural aroma & non-natural aroma & Chiral chromatography \\
Natural vanilla extract & Addition of artificial vanilla & IRMS and SNIF-NMR \\
Soybean & Genetic modification & DNA methods \\
\hline
\end{tabular}

Source: [9]. 


\subsection{Physical Methods}

There are various physical methods for detection of adulteration including microscopic and macroscopic visual structural analysis as well as analysis of food by analyzing the physical parameters like morphology, texture, solubility, bulk density etc. have been designed but these methods do not guarantee quantitative adulterant detection [7]. For instance, microscopic examination of some spices namely cumin,

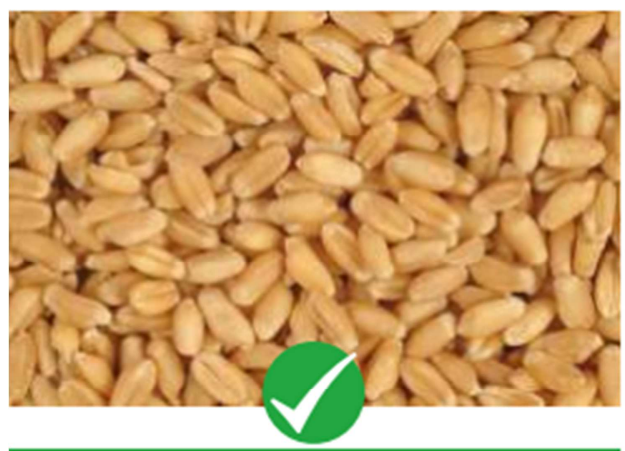

Pure coriander, chilies, and cloves lead to easy detection of extraneous starch in these powdered spices [13].

In grain, detection of adulteration with different impurities (dust, stones, straw, weed seeds, damaged grain, weevil grain, insects, rodent hair and excreta and etc) could be detected by taking small quantity of sample in a glass plate and examining the impurities visually because, pure food grains will not have any such impurities.

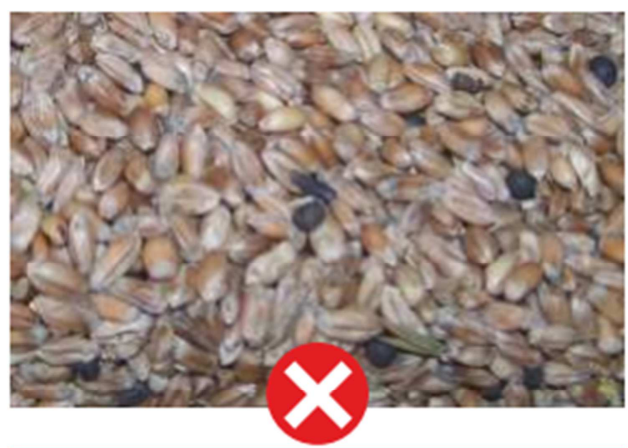

Adulterated

Source: http://foodsmart.fssai.gov.in/DART.pdf.

Figure 4. Detection of grains adulterated with impurities.

\subsection{Sensory Methods}

Traditionally, sensory methods have been employed in detecting some adulteration. Sensory methods however have not been incorporated yet into legislation for the detection of food adulteration, although routine analysis of a sample always includes the examination of its organoleptic characteristics. International organizations such as the International Standards Organization (ISO), American Society for Testing Materials (ASTM), and others have developed and recommended sensory methods for foods in general and for particular commodities [24]. Such methods are useful in trade (e.g., grading of goods) and the management of resources. Moreover, the US Food and Drug Administration (FDA) has accepted results of sensory panel tests as prima facie evidence of product efficacy, and in some cases, legal decisions in the USA have relied exclusively upon sensory evaluation data. The limitations concerning the application of sensory methods for the detection of adulteration are subjectivity of judgment and though it have fewer limitations that multivariate statistical techniques are employed ([24] and [27]). With these methods, sensory data are better evaluated, and more reliable conclusions can be drawn. For example, the results of Free-choice Profiling tests can be analyzed by the Generalized Procrustes method. The latter adjusts for several types of variation in the way each panelist describes samples and then manipulates the data to combine terms that appear to measure the same characteristics. Such an approach has been meaningfully applied to classify coffee, tea, and alcoholic beverages [24].

\section{Summary and Conclusion}

Food fraud is the deliberate substitution, addition, tampering or misrepresentation of food, food ingredients or food packaging, or false or misleading statements made about a product for economic gain. All most all food categories including milk, honey, butter, oil, cereals, pulses and etc. are prone to adulteration as indicated by different authors. The adulterated foods are made in the way that they can attract consumers so that; better price could be fetch from. However, the issue is, these foods may be adulterated in order to make them appealing types. These adulterations have many public health and economic implications. Different mechanisms of detecting adulteration are available ranging from chemical and instrumental analysis to sensory methods. Control of food adulteration needs attentions of different stake holder.

In conclusion, adulteration in developing country like ours is serious problem as there are less strong regulatory bodies unlike developed world. This is why there are limited reports in our country Ethiopia concerning the issue as can be understood from the review. There might be multiple factors contributing to this like economic problems common in developing countries which may lead to lack of facility for detection, awareness and small number of professionals with the discipline. Thus, much is expected to be done with adulteration in this country.

\section{Future Line of Work}

Different authors across the world have published their research work on the area of adulteration. Nevertheless, the area in our country, Ethiopia needs more and more efforts to identify different food products in our country that are prone to adulteration and recommend respective control measures. 
More research is needed on the detection methods of adulteration in indigenous foods like injera and others. That means, more methods need to be developed, validated and approved specially those which are simple and easy to undertake. Awareness creation for the community, food value chain stakeholders and different organizations and agencies responsible about health implication of adulteration and the like must be done.

\section{References}

[1] Alauddin S (2012). Food adulteration and society. Global research analysis international. Vol. 1 (7), pp 3-5.

[2] Anita, G. and Neetu, S., 2013. Hazards of New Technology in Promoting Food Adulteration. Journal of Environmental Science, Toxicology and Food Technology, 5 (1), pp. 08-10.

[3] Awasthi, S., Jain, K., Das, A., Alam, R., Surti, G. and Kishan, N., 2014. Analysis of Food quality and Food Adulterants from Different Departmental \& Local Grocery Stores by Qualitative Analysis for Food Safety. J Env Sci Toxicol Food Technol, 8 (2), pp. $22-26$.

[4] Asrat, A. and Yilma, Z., 2014. Patterns of milk and milk products adulteration in Boditti town and its surrounding, South Ethiopia. J Agric Sci, 4 (10), pp. 512-6.

[5] Asrat, A. and Ermias, B., E., 2015. Food Adulteration: Its Challenges and Impacts. Food Science and Quality Management, pp. 50-56.

[6] Ayalew, H., Birhanu, A. and Asrade, B. (2013). Review on food safety system: Ethiopian perspective. Afr. J. Food Sci. 7 (12): 431-440.

[7] Bansal, S., Apoorva, S., Manisha, M., Anupam, K M. and Sanjiv, K., 2015. Food Adulteration: Sources, Health Risks and Detection Methods. Critical Reviews in Food Science and Nutrition, DOI: 10.1080/10408398.2014.967834

[8] Biresaw, A. D., Woldemariam, H. W. and Abera, B. D., 2015. The Extent of Adulteration of Selected Foods at Bahir Dar, Ethiopia.

[9] Cordella, C., Moussa, I., Martel, A. C., Sbirrazzuoli, N. and Lizzani-Cuvelier, L., 2002. Recent developments in food characterization and adulteration detection: technique-oriented perspectives. Journal of agricultural and food chemistry, 50 (7), pp. 1751-1764

[10] Deepti Narayan, 2014, Food adulteration-Types, worldwide lows and future Category: Healthcare Views: 20277

[11] El-Loly, M., Mansour, A. I. A. and Ahmed, R. O., 2013. Evaluation of Raw Milk for Common Commercial Additives and Heat Treatments. Internet Journal of Food Safety, 15: $7-10$.

[12] Faraz, A., Lateef, M., Mustafa, M. I., Akhtar, P., Yaqoob, M. and Rehman, S., 2013. Detection of adulteration, chemical composition and hygienic status of milk supplied to various canteens of educational institutes and public places in Faisalabad. J Animal Plant Sci, 23 (1), pp. 119-24.

[13] Food safety \& standards authority of india (FSSAI), 2010 (ministry of health \& family welfare) fda bhavan, kotla road, new delhi - 110002 website: www.fssai.gov.in

[14] Khapre MP, Mudey A, Chaudhary S, Wagh V, Dawale A., 2011. Buying Practices and Prevalence of Adulteration in Selected Food items in a Rural Area of Wardha District: A Cross - Sectional Study. Online J Health Allied Scs. 2011; 10 (3): 4

[15] Kohda, Y. and Haque, I., 2017. Knowledge and Perception about Food Adulteration Problem among School Children in BangladeshIffat Haque. European Journal of Public Health, 27 (suppl_3).

[16] Lakshmi, V., 2012. Food adulteration. International Journal of Science Inventions Today, 1 (2), ppt. 106-113.

[17] Laura Schumm, 2014 Food Fraud: A Brief History of the Adulteration of Food

[18] Manasha, M. Janani, 2016. Food adulteration and its problems (intentional, accidental and natural food adulteration). International Journal of Research in Finance \& Marketing 6 (4): $131-140$

[19] Mansuri, Z. (2011). Study of adulterants in foods. Delhi, India.

[20] Matute, A. I., Soria, A. C., Martínez-Castro, I. and Sanz, M. L., 2007. A new methodology based on GC- MS to detect honey adulteration with commercial syrups. Journal of agricultural and food chemistry, 55 (18), pp. 7264-7269.

[21] Nielsen, S. S., 2010. Food Analysis, Food Science Texts Series, DOI 10.1007/978-1-4419-1478-1_6,. Fourth Edition ed. Purdue University, West Lafayette, $\overline{\mathrm{I}} \mathrm{N}$, USA: Springer.

[22] Raju, K., Shobham, A. R. and MK, S., 2017. Qualitative Detection of Some Adulterants in Milk Samples Supplied in the Twin Cities of Secunderabad and Hyderabad, Telangana.

[23] Tsimidou, M. and Boskou, D., 2003. Adulteration of foods/Detection 47.

[24] Vasireddi, 2013. Food Adulteration \& Control Mechanism; At the Workshop on Food Defense Awareness for Food Business Operators and Exporters February 5, 2013 - Hyderabad

[25] World Health Organization, 2017. Ten chemicals of major public health concern. Available from URL: http://www.who.int/ipcs/assessment/public_health/chemicals_ phe/en/

[26] Xue, H. Y., Hu, W. W., Son, H., Han, Y. and Yang, Z. Y., 2010. Indirect ELISA for detection and quantification of bovine milk in goat milk. Food Sci, 31, pp. 370-373.

[27] Fiorino, G. M., Garino, C., Arlorio, M., Logrieco, A. F., Losito, I. and Monaci, L., 2018. Overview on untargeted methods to combat food frauds: a focus on fishery products. Journal of food quality, 2018.

[28] Mahindru, S. N., 2013. Food preservation and irradiation. APH Publishing. 